\title{
Overexpression of SET oncoprotein is associated with tumor progression and poor prognosis in human gastric cancer
}

\author{
XIAONING YUAN $^{1 *}$, TE ZHANG $^{1 *}$, XIN ZHENG $^{2}$, YUNFEI ZHANG $^{1}$, TINGTING FENG $^{4}$, PENGFEI LIU $^{1}$, \\ ZHITING SUN ${ }^{1}$, SHANSHAN QIN ${ }^{1}$, XUEWEN LIU ${ }^{1}$, LIANG ZHANG ${ }^{1}$, JIE SONG $^{2,3}$ and YING LIU ${ }^{1}$ \\ ${ }^{1}$ Laboratory of Molecular Target Therapy of Cancer, Institute of Basic Medical Sciences, Hubei University of Medicine; \\ ${ }^{2}$ Department of Gastrointestinal Surgery, Dongfeng General Hospital, Hubei University of Medicine, Shiyan, Hubei 442000; \\ ${ }^{3}$ Department of Hematology, The Third Affiliated Hospital, Sun Yat-Sen University, Guangzhou, Guangdong 510630; \\ ${ }^{4}$ School of Basic Medical Sciences, Anhui Medical University, Hefei, Anhui 230032, P.R. China
}

Received January 11, 2017; Accepted June 22, 2017

DOI: $10.3892 /$ or.2017.5788

\begin{abstract}
SE translocation (SET) oncoprotein, an inhibitor of protein phosphatase $2 \mathrm{~A}$, is abnormally expressed in many cancers. In this study, SET was aberrantly upregulated in gastric cancer (GC) compared with control tissues. Clinicopathological analysis showed that SET expression was significantly correlated with pathological grade $(\mathrm{p}=0.002)$, lymph node stage $(\mathrm{p}=0.014)$, and invasive depth $(\mathrm{p}=0.022)$. Kaplan-Meier analysis indicated that patients with high SET expression showed poorer overall survival rates than those with low SET expression. Moreover, SET knockdown downregulated GC cell proliferation, colony formation, tumorigenesis, and metastasis. The biological effect of SET on proliferation and invasion was mediated by inhibition of protein phosphatase 2, which in turn, activated Akt. Taken together, our results suggested that SET overexpression is associated with GC progression, and it might be a potential diagnostic marker for GC, thereby a possible target for GC drug development.
\end{abstract}

\section{Introduction}

Gastric cancer (GC) is the fourth most common malignancy and third leading cause of cancer-related death worldwide, thereby representing a global cancer burden $(1,2)$. Although

Correspondence to: Dr Ying Liu, Laboratory of Molecular Target Therapy of Cancer, Institute of Basic Medical Sciences, Hubei University of Medicine, 30 South Renmin Road, Shiyan, Hubei 442000, P.R. China

E-mail: ying_liu1002@163.com

Dr Jie Song, Department of Hematology, The Third Affiliated Hospital, Sun Yat-Sen University, 600 Tianhe Road, Guangzhou, Guangdong 510630, P.R. China

E-mail: songjie1554@163.com

*Contributed equally

Key words: SET, gastric cancer, prognosis, metastasis, PP2A, Akt its incidence is decreased, the outcomes for GC patients remain unsatisfactory due to lack of effective biomarkers to detect early GC and predict both chemosensitivity and relapse. During the early disease, GC patients experience non-specific symptoms, and most patients are diagnosed with advanced GC because of lacking early-stage symptoms; late-stage diagnoses are generally considerably late for effective treatment and result in 5-year survival rate of $<20 \%$ (3). Therefore, new therapies toward molecular targets should be developed to improve the clinical outcome in GC.

Protein phosphatase 2A (PP2A), one of the main serinethreonine phosphatases, negatively regulates numerous signal transduction pathways and functions as a tumor suppressor in several cancers (4). Consistent with its role as a tumor suppressor, PP2A is crucial in the regulation of survival, cell cycle progression, and differentiation by negatively regulating the PI3K/Akt pathway (5), and dephosphorylating and inactivating ERK and MEK1 family kinases. Aberrant expression, mutations, and somatic alterations of PP2A scaffold and regulatory subunits are frequently found in human breast, lung, colon, and skin cancers (6). Thus, reactivation of PP2A activity based on its tumor suppressor properties is considered an attractive therapeutic strategy for human cancer treatment $(7,8)$.

SE translocation (SET) oncoprotein, an endogenous inhibitor of PP2A (9), was initially identified as a component of SET-CAN fusion gene produced by somatic translocation in acute, undifferentiated leukemia (10). It is a multifunctional protein, which belongs to the NAP1 family of histone chaperones. SET binds to nucleosomal histones and inhibits histone acetylation by masking histone tails as component of the INHAT complex (11). Recent reports revealed aberrant upregulation of SET in multiple cancer types; this protein is also a potential therapeutic target for cancer (12-18). SET is also involved in cell proliferation, apoptosis, and invasive behavior because it controls histone acetylation, $\beta$-adrenergic receptor phosphorylation, and granzyme activity (11-18). However, the role of SET in GC tumorigenesis and metastasis remains elusive.

In this study, we analyzed the expression of SET in GC specimens and established GC cell lines by western blot 
analysis and immunohistochemistry. We manipulated SET levels in different types of GC cells and measured their effect on tumorigenesis and metastasis in vitro and in vivo. To address possible mechanisms, the effect of SET on metastasis morphology and function was investigated. On the basis of our results, we propose that SET is essential in tumorigenesis and metastasis of GC by inhibiting PP2A.

\section{Materials and methods}

Patients. Two independent GC cohorts in tissue microarray (TMA) were utilized in this study. The training cohort TMA was purchased from Wuhan Iwill Biological Technology Co., Ltd. (Wuhan, China). It included 102 tissues of patients, and 25 paired non-cancerous normal tissues from these patients were also obtained. The array dot diameter was $1.5 \mathrm{~mm}$, and each dot represented a tissue spot from one individual specimen that was selected and pathologically confirmed. Six pairs of tumor and adjacent normal gastric tissues were collected immediately after surgical resection and stored in liquid nitrogen until further use. For western blot assay, tissue specimens were ground in liquid nitrogen-cooled mortar, tissue powder was suspended in lysis buffer $[50 \mathrm{mM}$ Tris- $\mathrm{HCl}(\mathrm{pH} 7.4), 150 \mathrm{mM} \mathrm{NaCl}, 1 \%$ Triton X-100, $1 \%$ sodium deoxycholate, $0.1 \%$ SDS, $1 \mathrm{mM}$ PMSF, complete protease inhibitor cocktail] and cleared by centrifugation. The samples were used by the approval of the Institutional Review Board of Hubei University of Medicine and Dongfeng General Hospital Affiliated to Hubei University of Medicine. All tissue samples were obtained with written informed consent from patients at the Dongfeng General Hospital.

Cell culture. The GC cell lines MKN74, SGC7901, BGC823, and MGC803 and normal human gastric epithelial cell line GES-1 were purchased from the American Tissue Culture Collection (ATCC, Manassas, VA, USA). SGC7901, BGC823, and GES-1 were cultured in Dulbecco's modified Eagle's medium (DMEM) containing 10\% fetal bovine serum (FBS; Hyclone Laboratories, Inc., Logan, UT, USA), 100 U/ml penicillin, $100 \mathrm{mg} / \mathrm{ml}$ streptomycin. MKN74 and MGC803 cells were cultured in RPMI-1640 (Hyclone Laboratories, Inc.) supplemented with 10\% FBS, $100 \mathrm{U} / \mathrm{ml}$ penicillin (Amresco, Cleveland, OH, USA), streptomycin $(100 \mathrm{mg} / \mathrm{ml})$ (Amresco). All cells were incubated in a humidified atmosphere with $\mathrm{CO}_{2}$ at $37^{\circ} \mathrm{C}$.

Real-time quantitative PCR ( $q P C R)$. Expression of the SET gene was examined by real-time polymerase chain reaction (PCR) normalized to expression of $\beta$-actin. Total RNA was extracted from cells using TRIzol reagent (Invitrogen; Thermo Fisher Scientifc, Inc., Waltham, MA, USA) according to the manufacturer's protocol. qPCR analysis of SET was performed with $2 \mu \mathrm{g}$ of total RNA and ReverTra Ace qPCR RT kit (Toyobo Co., Ltd. Life Science Department, Osaka Japan). Mixed $2 \mu \mathrm{g}$ RNA, $4 \mu \mathrm{l}$ 5X RT buffer, $1 \mu \mathrm{l}$ RT enzyme mix, $1 \mu \mathrm{l}$ primer mix, and nuclease-free water $\leq 20 \mu \mathrm{l}$ volume. The reverse transcription step as follows: $37^{\circ} \mathrm{C}$ for $15 \mathrm{~min} ; 98^{\circ} \mathrm{C}$ for $5 \mathrm{~min}$, then stored at $-20^{\circ} \mathrm{C}$. For qPCR, we used SET gene forward primer, 5'-AAATATAACAAACTCC GCCAACC-3'; reverse primer, 5'-CAGTGCCTCTTCATCTT
CCTC-3'. $\beta$-actin forward primer, 5'-GGCCAGGTCATCACC ATTG-3'; reverse primer, 5'-GGATGTCCACGTCACACT TCA-3'. RT-qPCR was performed in an ABI StepOnePlus ${ }^{\mathrm{TM}}$ Real-Time PCR system (ABI; Thermo Fisher Scientifc, Inc.) using SYBR ${ }^{\circledR}$ Green Real-time PCR Master Mix (Toyobo Co., Ltd. Life Science Department). Mixed SYBR Green PCR Master Mix $10 \mu \mathrm{l}$, forward and reverse primers $200 \mathrm{nM}$, cDNA template $100 \mathrm{ng}$, and $\mathrm{dd}_{2} \mathrm{O} \leq 20 \mu \mathrm{l}$ volume. PCR conditions consisted of the following: $95^{\circ} \mathrm{C}$ for $3 \mathrm{~min}$ for denaturation; $95^{\circ} \mathrm{C}$ for $15 \mathrm{sec}$ for annealing; and $60^{\circ} \mathrm{C}$ for $1 \mathrm{~min}$ for extension, for 40 cycles. The threshold cycle for each sample was selected from the linear range and converted to a starting quantity by interpolation from a standard curve generated on the same plate for each set of primers. The SET mRNA levels were normalized for each well to the $\beta$-actin mRNA levels using the $2^{-\Delta \Delta \mathrm{Cq}}$ method (19). Each experiment was repeated three times.

Western blot analysis. Cell pellets were lysed in RIPA buffer containing $50 \mathrm{mM}$ Tris, pH 8.0, $150 \mathrm{mM} \mathrm{NaCl}, 0.1 \%$ SDS, $0.5 \%$ deoxycholate, $1 \%$ NP-40, $1 \mathrm{mM}$ DTT, $1 \mathrm{mM} \mathrm{NaF}$, $1 \mathrm{mM}$ sodium vanadate, $1 \mathrm{mM}$ PMSF (Sigma-Aldrich; Merck Millipore, Darmstadt, Germany), and $1 \%$ protease inhibitors cocktail (Merck, Millipore). Lysates were normalized for total protein $(25 \mu \mathrm{g})$ and loaded on $8-12 \%$ sodium dodecyl sulfate polyacrylamide gel, electrophoresed, and transferred to a PVDF membrane (Millipore, Kenilworth, NJ, USA), followed by blocking with $5 \%$ skimmed milk at room temperature for $1 \mathrm{~h}$. The membrane was incubated with primary antibodies overnight at $4^{\circ} \mathrm{C}$ and rinsed with Tris-buffered saline with Tween-20. The primary antibodies used were anti- $\beta$-actin (1:50,000 dilution; cat. no. A3854) (Sigma-Aldrich); anti-SET (1:2,000 dilution; cat. no. 55201-1-AP), anti-c-Myc (1:2,000 dilution; cat. no. 10828-1-AP) (Proteintech); anti-MMP2 (1:2,000 dilution; cat. no. 2763-1) (Epitomics); anti-cyclin D1 (1:500 dilution; cat. no. sc-246), anti-phospho-Akt (S473) (1:500 dilution; cat. no. sc-7985), anti-Akt (1:500 dilution; cat. no. sc-8312) (Santa Cruz Biotechnology, Santa Cruz, CA, USA).

Immunohistochemistry. Immunohistochemical analysis as well as the scoring of immunoreactivity was performed using the rabbit polyclonal anti-SET antibody. Evaluation of immunostaining positive SET is found mainly in the cytoplasm. It was graded according to both the intensity and percentage of cells with positive staining. SET immunopositivity was graded in one to three tumor scores for each patient based on the intensity of the immunoreactivity in the cancer cells, that is, $3(+++)$ was strong, $2(++)$ was moderate, 1 was weak $(+)$, and 0 was negative. An optimal cutoff value was identified: a staining index of 2 was used to define tumors of high expression, and 1 or lower for low expression.

RNA interference. Using Lipofectamine ${ }^{\circledR} 3000$ Transfection reagent (Invitrogen, Carlsbad, CA, USA) according to the manufacturer's instructions, GC cells were transfected with shRNA expression vectorpGPU6/GFP/Neo-SET(GenePharma, Shanghai, China). The sequences were as follows: NC short hairpin RNA, 5'-GTTCTCCGAACGTGTCACGT-3'; shSET 1\#, 5'-GCCCTTCCTGTCTGAACAAAAAT-3'; 
shSET 2\#, 5'-GTGTACACAAAGGATTTGATGT-3'; and shSET 3\#, 5'-GGTGATCCATCTTCGAAGTCCT-3'. Also, $48 \mathrm{~h}$ after transfection the cells were harvested for western blot analysis, cell viability, and MTT assay. Cells were transfected with the lentivirus system (GenePharma). Transfection efficiency was assessed by western blot analysis and cell sorting, which was also used to select stably transfected cells.

Cytotoxic assay and cell viability. Cells were seeded into a 96-well plate and pre-cultured for $24 \mathrm{~h}$, and then transfected with plasmid or siRNA for 24 or $48 \mathrm{~h}$. Cell cytotoxicity was determined by MTT assay. The absorbance was measured at $570 \mathrm{~nm}$ by automated microplated reader (Bio-Tek, VT, USA), and the cell death rate was calculated as followed: inhibition rate $(\%)=$ (average $\mathrm{A}_{570}$ of the control group - average $\mathrm{A}_{570}$ of the experimental group) / (average $\mathrm{A}_{570}$ of the control group - average $\mathrm{A}_{570}$ of the blank group) $\mathrm{x} 100 \%$. Cell viability was estimated by trypan blue dye exclusion (20).

Soft-agar colony formation assay. Cells were suspended in $1 \mathrm{ml}$ of RPMI-1640 or DMEM containing $0.3 \%$ low-meltingpoint agarose (Amresco) and $10 \%$ FBS, and plated on a bottom layer containing $0.6 \%$ agarose and $10 \%$ FBS in 6-well plate in triplicate. After 2 weeks, plates were stained with $0.2 \%$ gentian violet and the colonies were counted under light microscope (IX70; Olympus Corp., Tokyo, Japan) (20).

Murine models. Equal number of female and male nude immunodeficient mice (nu/nu), 6-8 weeks old, were purchased from Hunan SJA Laboratory Animal Co., Ltd., and maintained and monitored in a specific pathogen-free environment. All animal studies were conducted according to protocols approved by the Hubei University of Medicine Animal Care and Use Committee, complying with the rules of Regulations for the Administration of Affairs Concerning Experimental Animals (Approved by the State Council of China). The mice were injected subcutaneously with SGC7901 (5x $10^{6}$ cells/mice) stably transfected with shSET or NC vectors in $100 \mu \mathrm{l}$ PBS were injected subcutaneously into the right flank of each mouse. Tumors were measured with a caliper and the volume calculated as follows: $4 \pi / 3 \times(\text { width } / 2)^{2} \times($ length $/ 2)$, representing the 3 -dimensional volume of an ellipse. After 30 days, the mice were euthanized by cervical dislocation and tumor tissues were excised, imaged, and weighed.

Invasion assay. An invasion assay was carried out using 24-well plate (Corning, Inc., Corning, NY, USA). A polyvinyl-pyrrolidone-free polycarbonate filter $(8-\mu \mathrm{m}$ pore size) (Corning) was coated with Matrigel (BD Biosciences, Franklin Lakes, NJ, USA). The lower chamber was filled with medium containing $20 \%$ FBS as chemoattractant. The coated filter and upper chamber were laid over the lower chamber. Cells $\left(1 \times 10^{4}\right.$ cells/well $)$ were seeded onto the upper chamber wells. After incubation for $20 \mathrm{~h}$ at $37^{\circ} \mathrm{C}$, the filter was fixed and stained with $2 \%$ ethanol containing $0.2 \%$ crystal violet (15 min). After being dried, the stained cells were enumerated under light microscope at 10x objective. For quantification, the invaded stained cells on the other side of the membrane were extracted with $33 \%$ acetic acid. The absorbance of the eluted stain was determined at $570 \mathrm{~nm}$.
Wound healing assay. Cells $\left(4 \times 10^{5}\right.$ cells $\left./ 2 \mathrm{ml}\right)$ were seeded in a 6-well plate and incubated at $37^{\circ} \mathrm{C}$ until $90-100 \%$ confluence. After the confluent cells were scratched with a $200-\mu 1$ pipette tip, followed by washing with PBS, and then treated with serum-free medium. After $24 \mathrm{~h}$ of incubation, the cells were fixed and stained with $2 \%$ ethanol containing $0.2 \%$ crystal violet powder (15 $\mathrm{min})$, and randomly chosen fields were photographed under a light microscope at $4 \mathrm{x}$ objective. The number of cells migrated into the scratched area was calculated.

PP2A activity assay. PP2A immunoprecipitation phosphatase assay kit (Upstate, Temecula, CA, USA) was used to measure phosphate release as an index of phosphatase activity according to the manufacturer's instructions. Briefly, $100 \mu \mathrm{g}$ protein isolated from cells was incubated with $4 \mu \mathrm{g}$ anti-PP2A monoclonal antibody overnight. Protein A agarose beads $(40 \mu \mathrm{l})$ were added and the mixture was incubated at $4^{\circ} \mathrm{C}$ for $2 \mathrm{~h}$. Subsequently, the beads were collected and washed three times with $700 \mu 1$ of ice-cold TBS and one time with $500 \mu \mathrm{l} \mathrm{Ser/Thr}$ assay buffer. The beads were further incubated with $750 \mathrm{mM}$ phosphopeptide in assay buffer for $10 \mathrm{~min}$ at $30^{\circ} \mathrm{C}$ with constant agitation. of Malachite Green Phosphate Detection solution $(100 \mu \mathrm{l})$ was added and the absorbance at $650 \mathrm{~nm}$ was measured on a microplate reader (21).

Statistical analysis. All experiments were repeated at least three times and the data are presented as the mean \pm SD unless noted otherwise. Differences between data groups were evaluated for significance using Student's t-test of unpaired data or one way analysis of variance and Bonferroni post hoc test. P-values $<0.05$ indicate statistical significance.

\section{Results}

SET is overexpressed and associated with poor prognosis in $G C$. We first investigated SET prevalence in a panel of 4 human GC cell lines (MKN74, SGC7901, BGC823 and MGC803) and 1 normal human gastric epithelial cell line GES-1. Real-time quantitative PCR (qPCR, Fig. 1A) and western blot analysis (Fig. 1B) showed high level of SET in SGC7901, BGC823, and MGC803 cells compared with that in GES-1 $(p<0.05)$. We investigated the activity of PP2A in the above cell lines and found that GC lines have lower PP2A activity than GES-1 (Fig. 1C). We detected SET expression in clinical samples of human GC by qPCR and western blot analysis. The results showed that SET was upregulated in the majority of tested specimens (5 out of 6) compared with that in patient-matched adjacent normal gastric tissues $(\mathrm{p}<0.05$, Fig. 1D and E). We also analyzed SET expression in $102 \mathrm{GC}$ specimens and 25 adjacent normal tissues using immunohistochemistry analysis. To evaluate the role of SET expression in GC tumorigenesis, we divided the GC patients into SET high (+++), moderate (++), and low expression (+) groups by immunohistochemical assay. Immunoreactivity scoring was performed as described (22). We found that SET was overexpressed in $46 \%$ of tumor samples (47 of 102), and the adjacent normal tissues exhibited low (or moderate) SET staining (21 of 25) (Fig. 1F and G). These results suggested that SET 
A

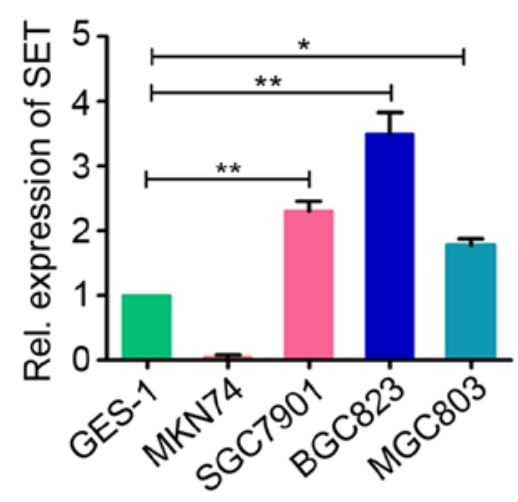

B
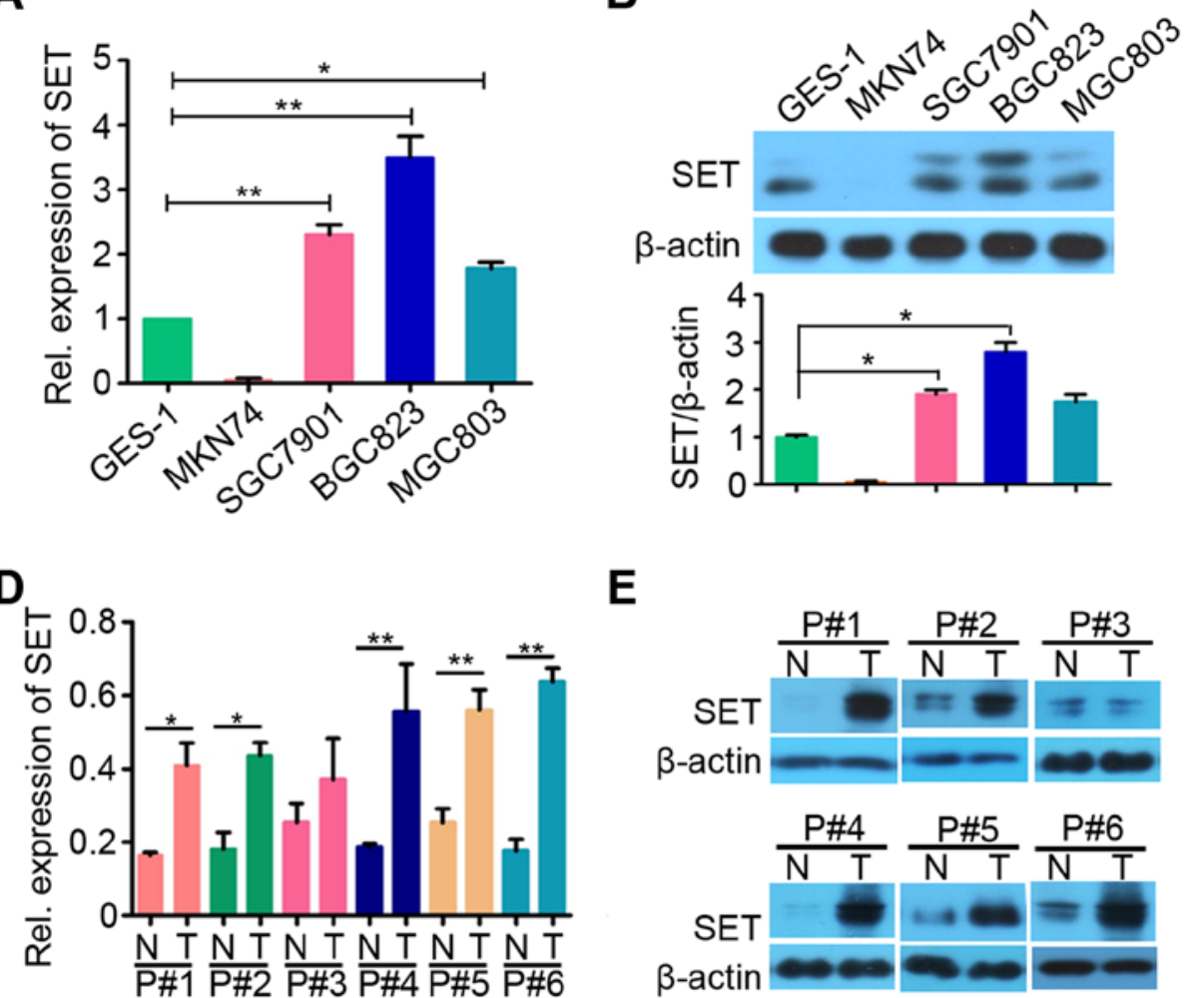

E

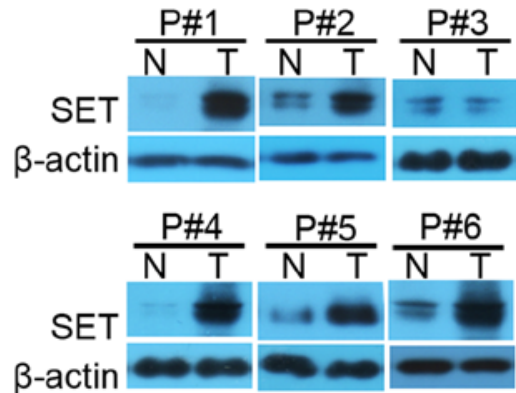

C

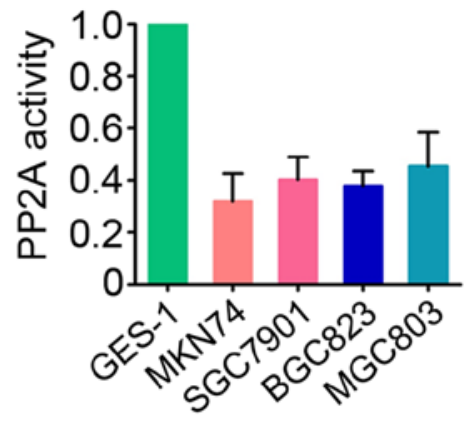

F

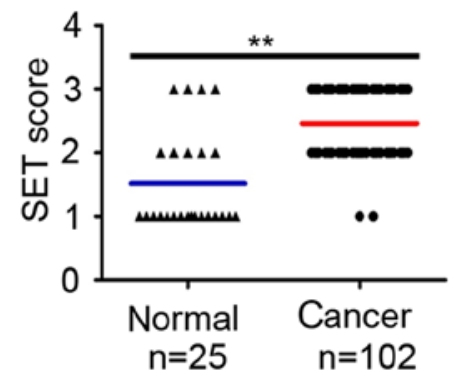

G

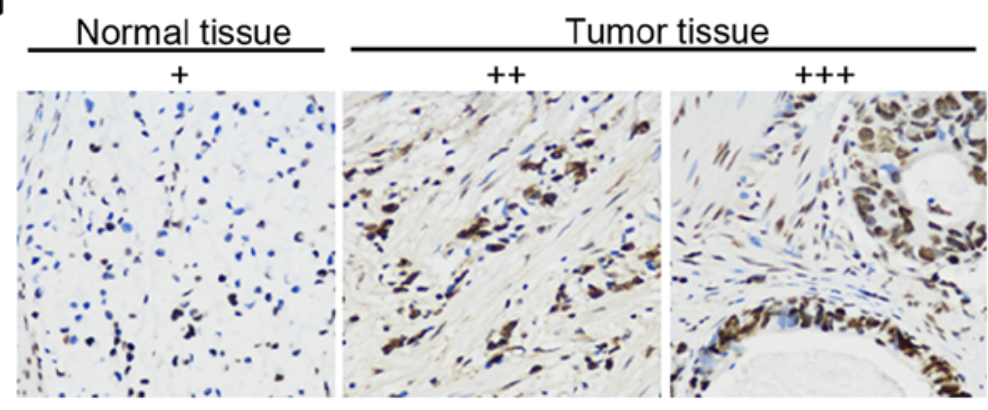

H

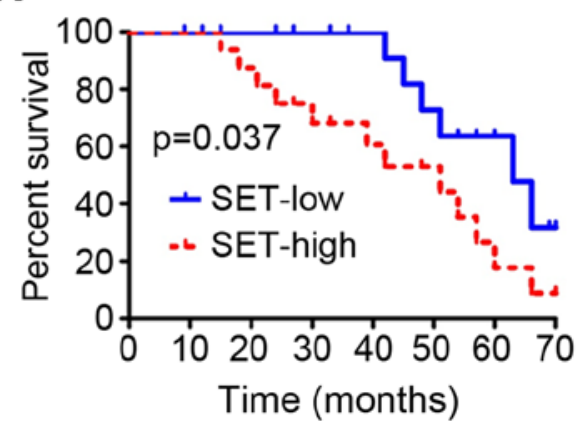

Figure 1. SET is overexpressed and associated with prognosis in GC. (A) qPCR analysis of SET mRNA levels in normal human gastric epithelial cell line GES-1 and GC cell lines. $\beta$-actin was used as a loading control. ${ }^{*} \mathrm{p}<0.05 ;{ }^{* *} \mathrm{p}<0.01$. (B) Western blot analysis of SET protein levels in GES-1 and GC cell lines. (C) GC cell lines were lysed, and cell lysates were prepared for detecting PP2A activity. (D) qPCR analysis of SET mRNA levels in primary gastric tumors (T) and normal gastric tissues $(\mathrm{N})$. $\beta$-actin was used as a loading control and numbers represent individual patients. ${ }^{*} \mathrm{p}<0.05$; ${ }^{* *} \mathrm{p}<0.01$. (E) Western blot analyses of SET protein in primary gastric tumors (T) and normal gastric tissues (N). (F) Immunohistochemistry analysis of SET protein levels in GC specimens and normal tissues. The GC tissue sections were quantitatively scored according to the percentage of positive cells and staining intensity as described in Materials and methods. The percentage and intensity scores were multiplied to obtain a total score (range, 0-3), and the tumors were finally determined as negative (-), score 0; lower expression (+), score 1; moderate expression (++), score 2; and high expression (+++), score 3. SET expression scores in GC specimens and normal tissues. $(G)$ Representative immunohistochemical staining examples of SET protein expression in normal tissues and two different GC tissues. (H) Survival curves of GC patients with low expression versus high expression of SET ( $\mathrm{p}=0.037)$.

might be a critical molecule in GC development. Survival analysis revealed that GC patients with high SET expression exhibited poorer overall survival than those with low SET expression ( $\mathrm{p}=0.037$; Fig. $1 \mathrm{H})$. Furthermore, we analyzed the relationship between SET expression levels and clinicopathological characteristics. As shown in Table I, SET expression and sex, age, clinical stage, or tumor size at diagnosis showed no statistically significant correlations ( $p>0.05)$. Nevertheless, statistically significant correlations among high levels of SET expression were found with pathological grade $(p=0.002)$, lymph node stage $(\mathrm{p}=0.014)$, and invasive depth $(\mathrm{p}=0.022)$.
Altogether, these data suggested that SET is overexpressed in GC, and high level of SET expression is a prognostic predictor of progression and poor prognosis of GC patients.

Knockdown of SET inhibits GC cell proliferation and tumorigenesis. We also evaluated the functional role of SET in GC proliferation and tumorigenesis. GC cell lines were transfected with negative control (NC) or SET-specific shRNA (shSET) vectors (Fig. 2A). MTT and clonogenic assay were used to investigate the involvement of SET in tumorigenesis. Knockdown of SET significantly decreased 
Table I. Characteristics of SET expression in GC patients.

\begin{tabular}{|c|c|c|c|c|}
\hline \multirow[b]{2}{*}{ Characteristics } & \multirow[b]{2}{*}{$\begin{array}{c}\text { All }(\mathrm{n}=102) \\
\text { No. }\end{array}$} & \multicolumn{2}{|c|}{ SET expression } & \multirow[b]{2}{*}{ P-value ${ }^{a}$} \\
\hline & & $\begin{array}{c}\text { Low }(n=55) \\
\text { No. }\end{array}$ & $\begin{array}{c}\text { High }(n=47) \\
\text { No. }\end{array}$ & \\
\hline \multicolumn{5}{|l|}{ Age } \\
\hline$<60$ & 72 & 37 & 35 & 0.427 \\
\hline$\geq 60$ & 30 & 18 & 12 & \\
\hline \multicolumn{5}{|l|}{ Sex } \\
\hline Male & 73 & 38 & 35 & 0.548 \\
\hline Female & 29 & 17 & 12 & \\
\hline \multicolumn{5}{|l|}{ Clinical stage } \\
\hline Early (IA-IIB) & 33 & 16 & 17 & 0.446 \\
\hline Advanced (IIIA-IV) & 69 & 39 & 30 & \\
\hline \multicolumn{5}{|l|}{ Pathological grade } \\
\hline I-II & 17 & 15 & 2 & 0.002 \\
\hline III-IV & 85 & 40 & 45 & \\
\hline \multicolumn{5}{|l|}{ Invasive depth } \\
\hline $\mathrm{T} 1-\mathrm{T} 2$ & 21 & 16 & 5 & 0.022 \\
\hline $\mathrm{T} 3-\mathrm{T} 4$ & 81 & 39 & 42 & \\
\hline \multicolumn{5}{|l|}{ Lymph node stage } \\
\hline No & 27 & 20 & 7 & 0.014 \\
\hline N1-N3 & 75 & 35 & 40 & \\
\hline \multicolumn{5}{|l|}{ Tumor size } \\
\hline$<7 \mathrm{~cm}$ & 83 & 41 & 42 & 0.055 \\
\hline$\geq 7 \mathrm{~cm}$ & 19 & 14 & 5 & \\
\hline
\end{tabular}

${ }^{a}$ Chi-sqaure test.

cell viability (Fig. 2B) in MGC803, SGC7901, and BGC823 cells compared with that of the NC group. Furthermore, colony formation was reduced after transfection with SET shRNA (Fig. 2C). To further determine the importance of SET in tumorigenesis, we investigated the effect of SET knockdown on tumor growth in vivo. SGC7901 cells stably expressing NC or shSET were injected subcutaneously into the right flanks of nude mice. SET knockdown substantially inhibited in vivo tumor growth on SGC7901 cells (Fig. 2D-F).

Knockdown of SET suppresses GC cell invasion and migration. To examine the role of SET in GC cell metastasis, we evaluated the effect of SET knockdown on GC cell invasion and migration by Transwell and wound healing assays. As shown in Fig. 3A, SET knockdown drastically reduced the invasive ability of MGC803, BGC823, and SGC7901 cells compared with that of NC. Wound healing assay also showed that knockdown of SET significantly decreased the migratory rate of MGC803, BGC823, and SGC7901 cells (Fig. 3B). We also evaluated the effects of SET on the expression of several proliferative and invasive protein markers. Western blot analysis revealed that knockdown of SET markedly suppressed the protein expression of c-Myc and cyclin D1 and decreased the expression of matrix metalloproteinase 2 (MMP2) (Fig. 3C). c-Myc is a target of PP2A (23). Moreover, SET participates in the regulation of cellular molecular processes by inhibiting the tumor suppressor PP2A (9). Thus, we analyzed whether SET silence can alter the effects of PP2A in GC cells. SET depletion significantly upregulated the phosphatase activity of MGC803, BGC823 and SGC7901 cells (Fig. 3D). In addition, we used western blot analysis to investigate Akt phosphorylation (pAkt) and found that SET silence also reduced pAkt, a critical PP2A target (Fig. 3C).

Inhibition of PP2A is essential for SET-induced proliferation and metastasis. To further evaluate whether SET-induced cell proliferation is caused by the inhibition of PP2A activity, we compared cell proliferation in shSET-transfected GC cells and NC-transfected GC cells in the presence and absence of PP2A inhibitor, that is, okadaic acid (OA). OA significantly reversed the cell proliferation inhibited by SET silence (Fig. 4A). In addition, we compared cell proliferation in shSET-transfected GC cells and NC-transfected GC cells in the presence and absence of PP2A activator FTY720. FTY720 significantly enhances 
A

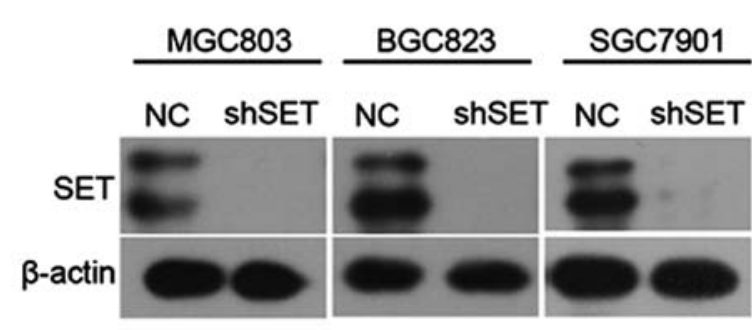

C

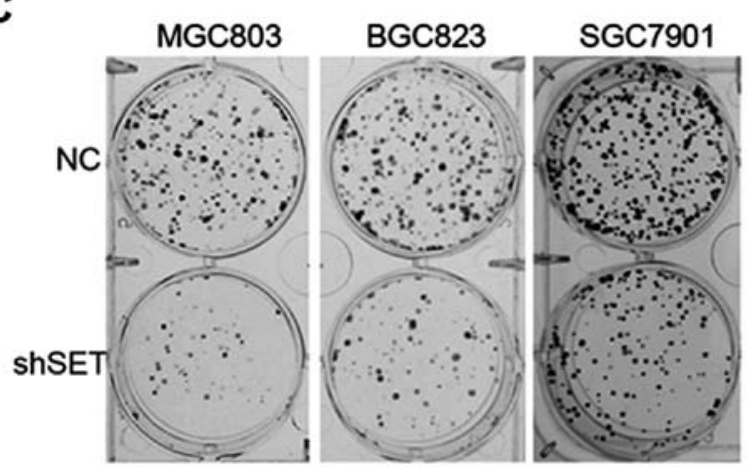

B
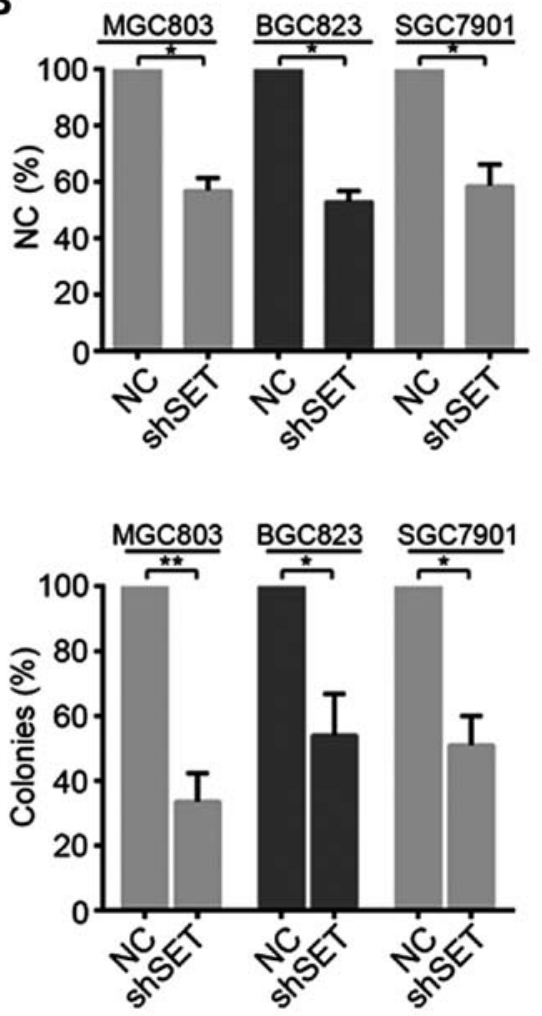

D

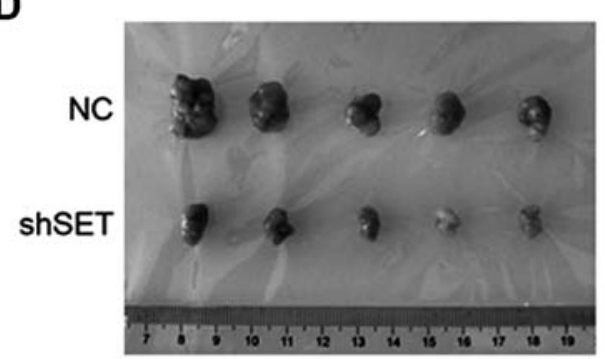

E

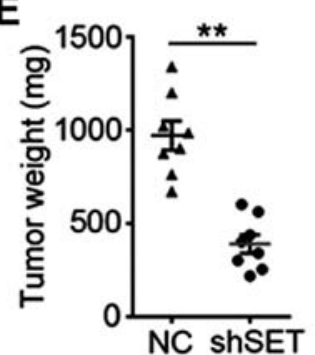

F

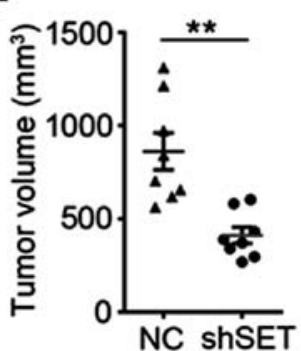

Figure 2. Knockdown of SET suppresses the proliferation of GC cells. (A) MGC803, BGC823, and SGC7901 cells were transfected with control (NC) or shSET vectors and SET expression was analyzed by western blot analysis. (B) MGC803, BGC823, and SGC7901 cells were transfected with NC or shSET for $48 \mathrm{~h}$, cell viability was evaluated by MTT assay. (C) Colony forming ability of MGC803, BGC823, and SGC7901 cells transfected with NC or shSET. (D and E) SGC7901 cells stably transfected with NC or shSET vectors were injected subcutaneously into nude mice. The final tumor weight and tumor volume are shown with images of xenograft tumors. Values represent the mean \pm SEM; $n=8 ;{ }^{*} p<0.05,{ }^{* *} p<0.01$.

the cell proliferation inhibited by SET silence (Fig. 4B). Furthermore, OA also significantly reversed the cell invasion and migration inhibited by SET silence (Fig. 4C and D). Hence, inhibition of PP2A is, at least in part, essential for SET-induced proliferation and metastasis.

\section{Discussion}

As one of the most common human malignancies in China, $\mathrm{GC}$ remains as a challenging disease. Complete resection is the primary treatment of localized tumors, but patients who are newly diagnosed with GC tend to present advanced and often incurable diseases (24). Therefore, novel diagnostic markers, molecular pathways implicated in GC pathogenesis, and targeted therapy should be developed urgently. This report is the first to demonstrate that SET expression is significantly upregulated in GC cell lines and cancer tissues at both protein and mRNA levels in comparison with those of normal cells and paired adjacent non-cancerous gastric tissues. We found that high expression of SET was correlated with pathological grade, lymph node stage, and invasive depth. SET also played an oncogenic role of promoting cell proliferation, colony formation, and metastasis. Furthermore, SET was required for tumorigenesis of GC.

SET is a predictive marker for prognosis in Wilm tumor (12), pancreatic tumor (13), prostate cancer (14), ovarian cancer (15), lung tumor (16), acute myelogenous leukemia (17), and chronic lymphocytic leukemia (18). Overexpression of SET oncoprotein in these cancer cells decreases PP2A activity and promotes cell proliferation, survival, drug resistance, invasion, and metastasis. In this study, SET was overexpressed in all GC cell lines, but showed low expression in normal gastric epithelial cells, thereby suggesting that SET has a positive role in GC formation (Fig. 1A and B). In addition, GC samples expressed high levels of SET compared with those of adjacent normal gastric tissues (Fig. 1C-F). Multivariate analysis indi- 
A

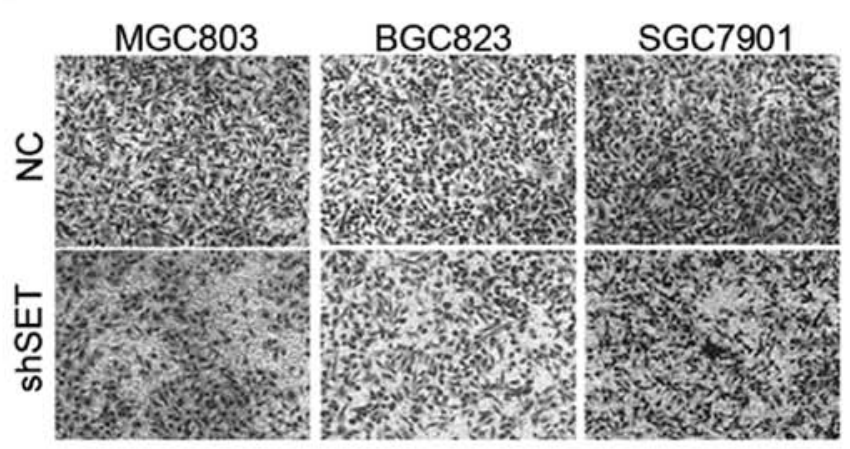

B
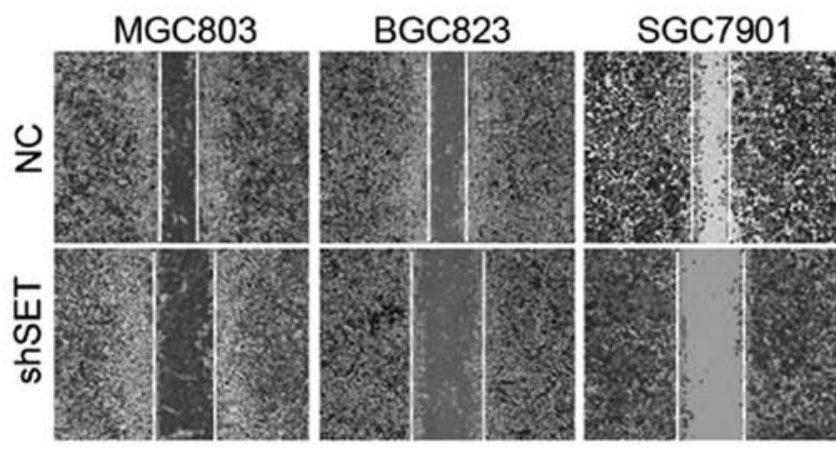

C

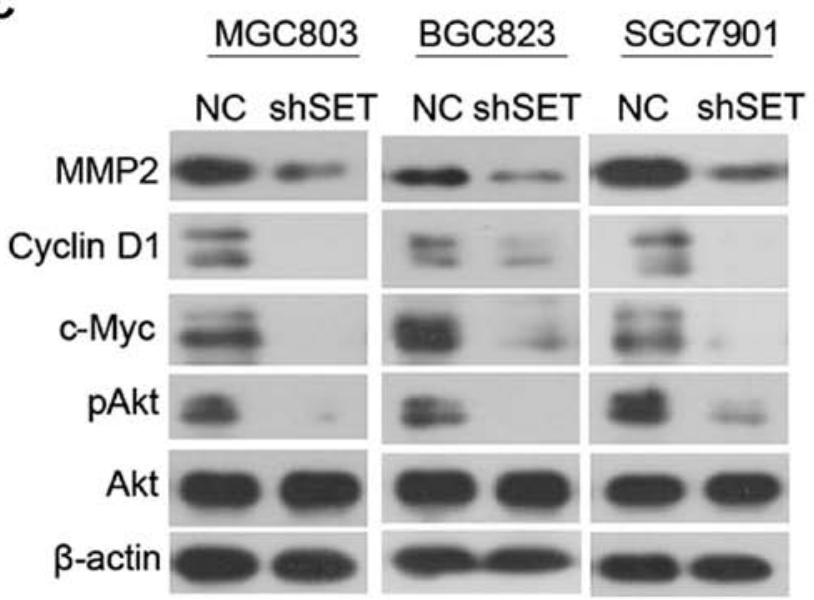

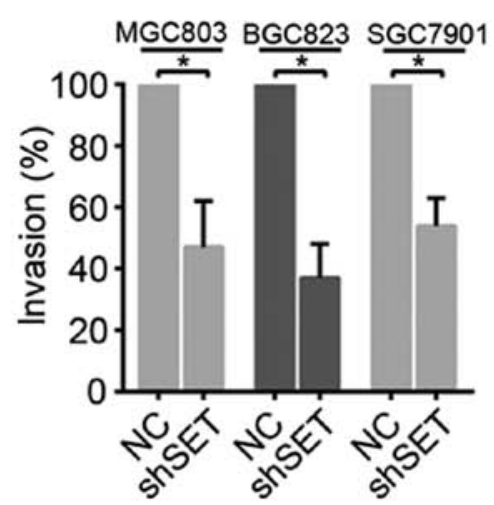

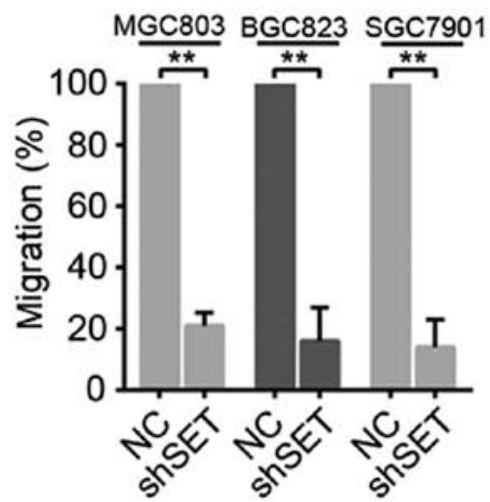

D

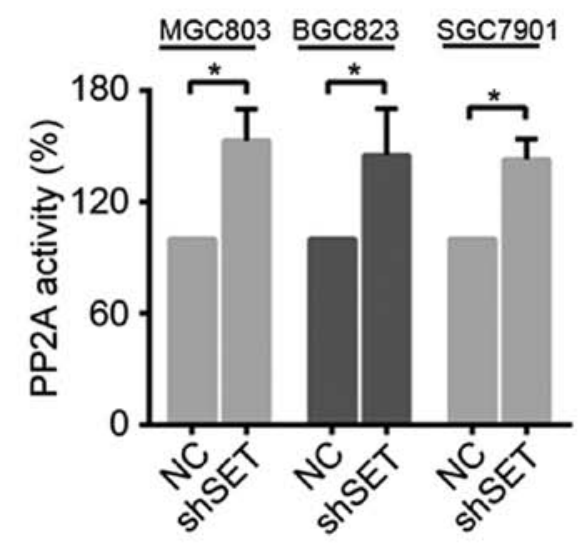

Figure 3. Knockdown of SET suppresses the invasion and migration of GC cells. (A) MGC803, BGC823, and SGC7901 cells were transfected with shSET, cell invasive ability was detected by Matrigel Transwell assays. * $p<0.05$. (B) The migratory speed of shSET-expressing MGC803, BGC823, and SGC7901 cells was monitored through a wound healing assay. ${ }^{* *}$ p $<0.01$. (C) MGC803, BGC823, and SGC7901 cells were transfected with shSET, western blot analysis was performed using antibodies indicated. (D) MGC803, BGC823, and SGC7901 cells transfected with shSET for $48 \mathrm{~h}$ and lysed, and cell lysates were prepared for detecting PP2A activity as described in Materials and methods. ${ }^{*} \mathrm{p}<0.05$.

cated that SET was closely associated with tumor progression and poor prognosis (Fig. $1 \mathrm{G}$ and Table I), and SET may represent an independent prognostic biomarker for GC patients. SET knockdown attenuated the tumorigenicity of SGC7901 cells in nude mice, which suggested that SET is required in $\mathrm{GC}$ tumorigenesis and progression, which is consistent with previous findings (Fig. 2D-F).

Invasion and migration are important characteristics of cancer cell metastasis (25). To determine the potential mechanisms of GC, we further tested the effect of SET knockdown on migration and invasion. Wound healing and Transwell assay data indicated that silencing of SET in GC cells could efficiently inhibit the invasive capability of GC cells (Fig. 3A and B). Downregulation of SET also inhibited the expression of cyclin D1, MMP2, c-Myc, and pAkt and upregulated the activity of PP2A (Fig. 3C and D). These abnormally expressed downstream molecules of CIP2A are critical for GC proliferation and metastasis.

PP2A, one of the four major classes (PP1, PP2A, PP2B, and $\mathrm{PP} 2 \mathrm{C}$ ) of eukaryotic serine/threonine phosphoprotein phosphatases, is a key tumor suppressor that regulates survival, cell cycle progression, and differentiation-related signaling pathways with 
A

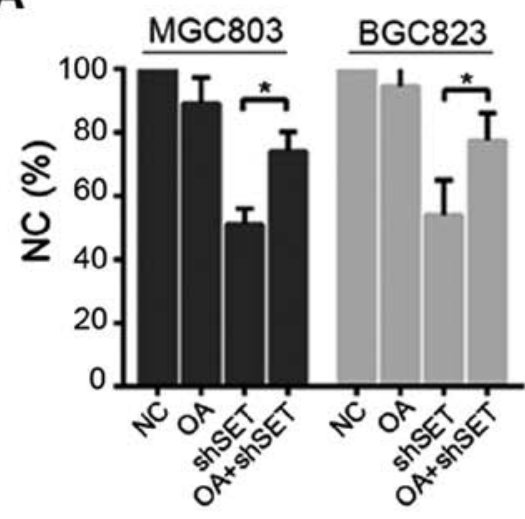

B

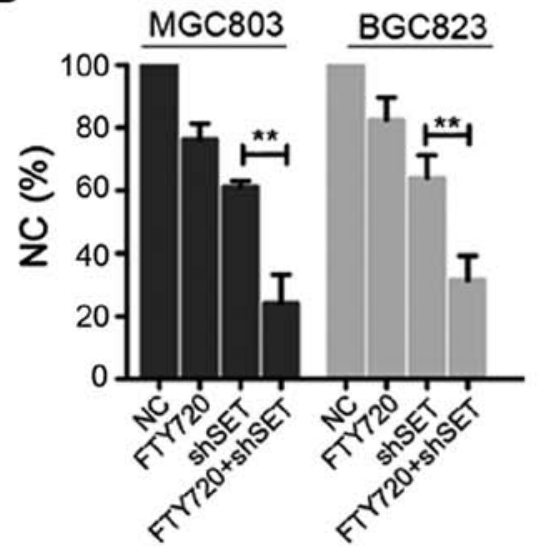

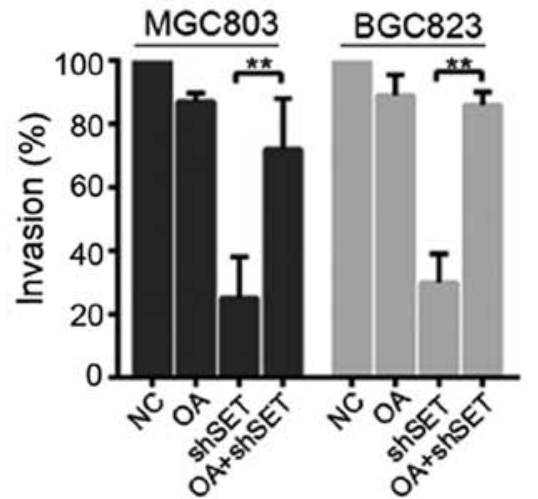

C
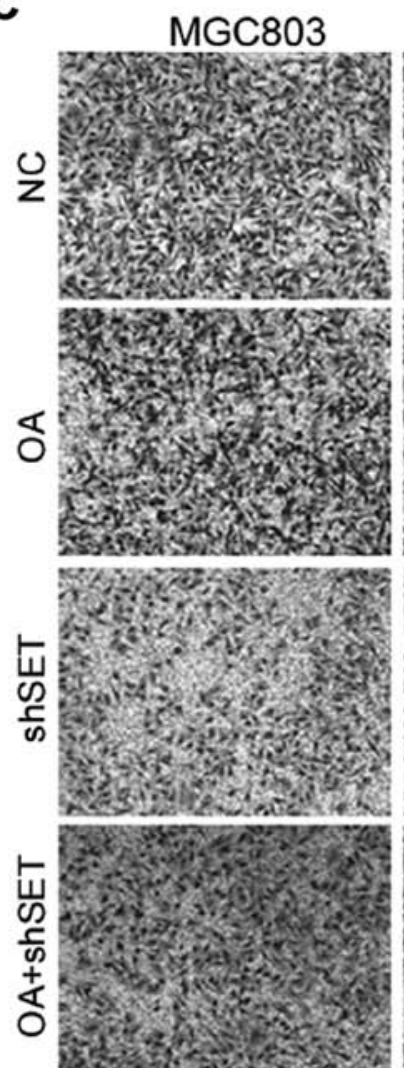

BGC823
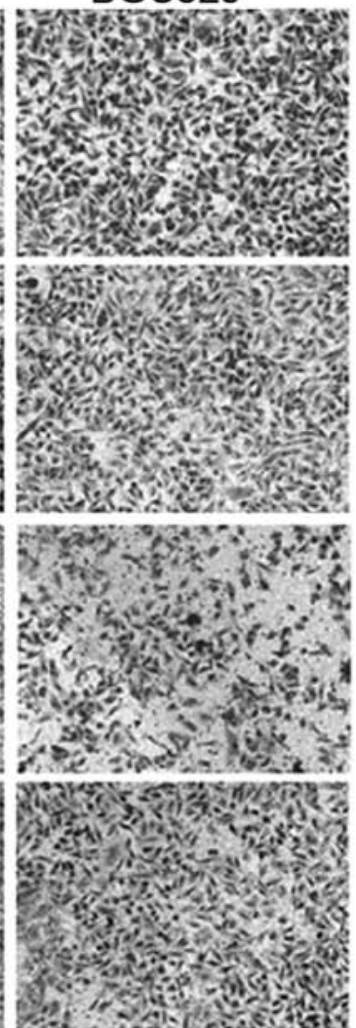

D
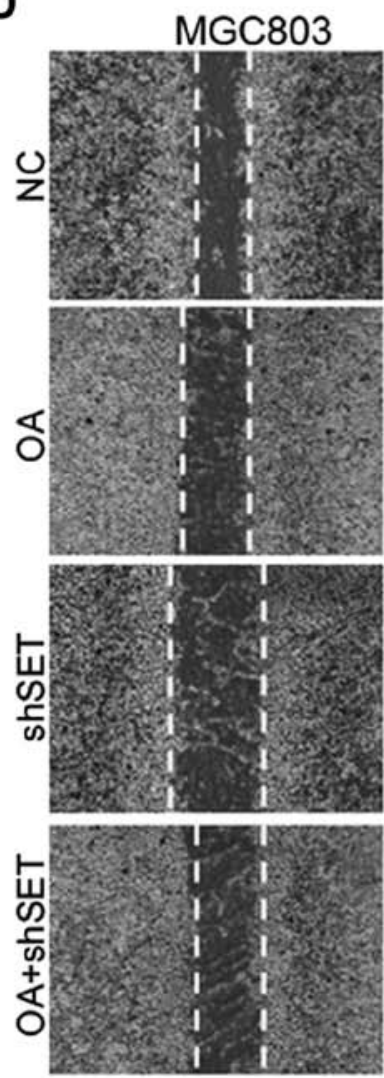

BGC823
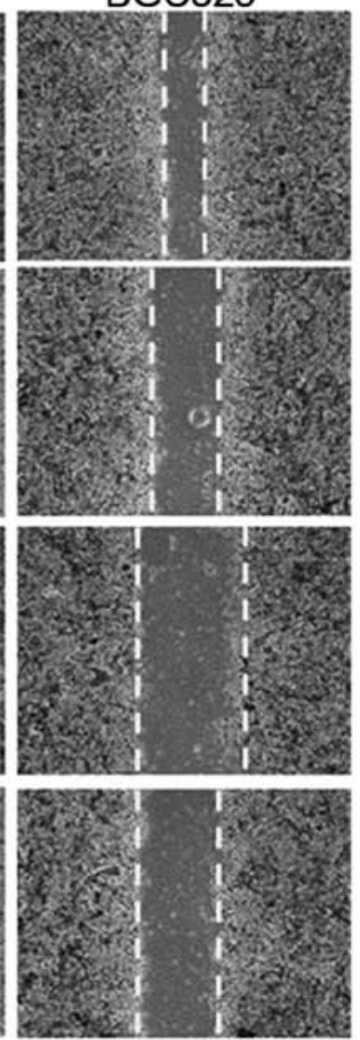

Figure 4. SET promotes proliferation and metastasis through inhibiting PP2A. (A) MGC803, or BGC823 cells were transfected with shSET (or NC), $6 \mathrm{~h}$ after transfection, cells were treated with or without $0.5 \mathrm{nM} \mathrm{OA}$ for $48 \mathrm{~h}$, cell viability was evaluated by MTT assay. *p<0.05. (B) MGC803, or BGC823 cells were transfected with shSET (or NC), $6 \mathrm{~h}$ after transfection, cells were treated with or without $2.5 \mu \mathrm{M}$ FTY720 for $48 \mathrm{~h}$, cell viability was evaluated by MTT assay. ${ }^{* *} \mathrm{p}<0.01$. (C) MGC803 or BGC823 cells were transfected with shSET (or NC), $6 \mathrm{~h}$ after transfection, cells were treated with or without $0.5 \mathrm{nM}$ OA for $48 \mathrm{~h}$, cell invasive ability was detected by Matrigel Transwell assay. ${ }^{* *} \mathrm{p}<0.01$. (D) MGC803 or BGC823 cells were transfected with shSET (or NC), $6 \mathrm{~h}$ after transfection, cells were treated with or without $0.5 \mathrm{nM}$ OA for $48 \mathrm{~h}$, cell migration ability was detected by wound healing assay.

high relevance in human cancer $(4,23)$. SET oncoprotein is an important binding partner of PP2A with an inhibitory function, and collected evidence supports the idea that SET-promoted tumor progression is mediated by PP2A inhibition (16). We treated OA, the inhibitor of PP2A in SET-depleted GC cells. The results showed that loss of PP2A function can reverse the inhibition effect of SET depletion in GC cell proliferation, migration, and invasion (Fig. 4A-C). These results confirmed that PP2A inactivation plays a critical role in SET-promoted GC proliferation and invasion progression. PP2A-activating drugs represent promising anticancer molecules that can be used in cancer treatment $(16,26,27)$. Thus, targeting SET protein is a potential strategy to treat cancer by reactivation of PP2A.

In conclusion, high expression of SET is a recurrent event in GC, where it serves as a marker of reduced overall survival and a poor prognostic factor, as previously reported in other tumors. Moreover, SET depletion upregulates PP2A activity, thereby reducing cell proliferation, invasion, and migration. Our results confirmed that SET behaves as an oncoprotein in GC and could represent a novel therapeutic target in GC. 


\section{Acknowledgements}

This study was supported by grants from the National Natural Sciences Foundation of China (grant no. 81400157); the Natural Science Foundation of Hubei Province of China (grant no. 2016CFB528); the Foundation of Health and Family planning Commission of Hubei Province (grant no., WJ2017F065 and WJ2017F067); the Foundation of Hubei University of Medicine (grant no. FDFR201605) and the National Training Program of Innovation and Entrepreneurship for undergraduates (grant nos. 201710929004 and 201710929012).

\section{References}

1. Kanda M and Kodera Y: Recent advances in the molecular diagnostics of gastric cancer. World J Gastroenterol 21: 9838-9852, 2015.

2. Siegel RL, Miller KD and Jemal A: Cancer statistics, 2015. CA Cancer J Clin 65: 5-29, 2015.

3. Jemal A, Tiwari RC, Murray T, Ghafoor A, Samuels A, Ward E, Feuer EJ and Thun MJ; American Cancer Society: Cancer statistics, 2004. CA Cancer J Clin 54: 8-29, 2004.

4. Perrotti D and Neviani P: Protein phosphatase 2A: A target for anticancer therapy. Lancet Oncol 14: e229-e238, 2013.

5. Junttila MR, Puustinen P, Niemelä M, Ahola R, Arnold H, Böttzauw T, Ala-aho R, Nielsen C, Ivaska J, Taya Y, et al: CIP2A inhibits PP2A in human malignancies. Cell 130: 51-62, 2007.

6. Seshacharyulu P, Pandey P, Datta K and Batra SK: Phosphatase: PP2A structural importance, regulation and its aberrant expression in cancer. Cancer Lett 335: 9-18, 2013.

7. Schönthal AH: Role of serine/threonine protein phosphatase $2 \mathrm{~A}$ in cancer. Cancer Lett 170: 1-13, 2001.

8. Lv P, Wang Y, Ma J, Wang Z, Li JL, Hong CS, Zhuang Z and Zeng YX: Inhibition of protein phosphatase $2 \mathrm{~A}$ with a small molecule LB100 radiosensitizes nasopharyngeal carcinoma xenografts by inducing mitotic catastrophe and blocking DNA damage repair. Oncotarget 5: 7512-7524, 2014

9. Li M, Makkinje A and Damuni Z: The myeloid leukemia-associated protein SET is a potent inhibitor of protein phosphatase 2A. J Biol Chem 271: 11059-11062, 1996.

10. Adachi Y, Pavlakis GN and Copeland TD: Identification and characterization of SET, a nuclear phosphoprotein encoded by the translocation break point in acute undifferentiated leukemia. J Biol Chem 269: 2258-2262, 1994.

11. Kalousi A, Hoffbeck AS, Selemenakis PN, Pinder J, Savage KI, Khanna KK, Brino L, Dellaire G, Gorgoulis VG and Soutoglou E: The nuclear oncogene SET controls DNA repair by KAP1 and HP1 retention to chromatin. Cell Rep 11: 149-163, 2015.

12. Carlson SG, Eng E, Kim EG, Perlman EJ, Copeland TD and Ballermann BJ: Expression of SET, an inhibitor of protein phosphatase 2A, in renal development and Wilms' tumor. J Am Soc Nephrol 9: 1873-1880, 1998.

13. Bhutia YD, Hung SW, Krentz M, Patel D, Lovin D, Manoharan R, Thomson JM and Govindarajan R: Differential processing of let-7a precursors influences RRM2 expression and chemosensitivity in pancreatic cancer: Role of LIN-28 and SET oncoprotein PLoS One 8: e53436, 2013.
14. Anazawa Y, Nakagawa H, Furihara M, Ashida S, Tamura K, Yoshioka H, Shuin T, Fujioka T, Katagiri T and Nakamura Y: PCOTH, a novel gene overexpressed in prostate cancers, promotes prostate cancer cell growth through phosphorylation of oncoprotein TAF-Ibeta/SET. Cancer Res 65: 4578-4586, 2005.

15. Ouellet V, Page CL, Guyot M-C, Lussier C, Tonin PN, Provencher DM and Mes-Masson A-M: SET complex in serous epithelial ovarian cancer. Int J Cancer 119: 2119-2126, 2006.

16. Liu H, Gu Y, Wang H, Yin J, Zheng G, Zhang Z, Lu M, Wang C and $\mathrm{He} \mathrm{Z}$ : Overexpression of PP2A inhibitor SET oncoprotein is associated with tumor progression and poor prognosis in human non-small cell lung cancer. Oncotarget 6: 14913-14925, 2015.

17. Cristóbal I, Garcia-Orti L, Cirauqui C, Cortes-Lavaud X, GarcíaSánchez MA, Calasanz MJ and Odero MD: Overexpression of SET is a recurrent event associated with poor outcome and contributes to protein phosphatase $2 \mathrm{~A}$ inhibition in acute myeloid leukemia. Haematologica 97: 543-550, 2012.

18. Christensen DJ, Chen Y, Oddo J, Matta KM, Neil J, Davis ED, Volkheimer AD, Lanasa MC, Friedman DR, Goodman BK, et al: SET oncoprotein overexpression in B-cell chronic lymphocytic leukemia and non-Hodgkin lymphoma: A predictor of aggressive disease and a new treatment target. Blood 118: 4150-4158, 2011.

19. Livak KJ and Schmittgen TD: Analysis of relative gene expression data using real-time quantitative PCR and the 2(-Delta Delta C(T)) method. Methods 25: 402-408, 2001.

20. Cao W, Liu Y, Zhang R, Zhang B, Wang T, Zhu X, Mei L, Chen H, Zhang H, Ming P, et al: Homoharringtonine induces apoptosis and inhibits STAT3 via IL-6/JAK1/STAT3 signal pathway in Gefitinib-resistant lung cancer cells. Sci Rep 5: 8477, 2015.

21. Xiao X, He Z, Cao W, Cai F, Zhang L, Huang Q, Fan C, Duan C, Wang $\mathrm{X}$, Wang $\mathrm{J}$, et al: Oridonin inhibits gefitinib-resistant lung cancer cells by suppressing EGFR/ERK/MMP-12 and CIP2A/ Akt signaling pathways. Int J Oncol 48: 2608-2618, 2016.

22. Khanna A, Böckelman C, Hemmes A, Junttila MR, Wiksten JP, Lundin M, Junnila S, Murphy DJ, Evan GI, Haglund C, et al: MYC-dependent regulation and prognostic role of CIP2A in gastric cancer. J Natl Cancer Inst 101: 793-805, 2009.

23. Rincón R, Cristóbal I, Zazo S, Arpí O, Menéndez S, Manso R, Lluch A, Eroles P, Rovira A, Albanell J, et al: PP2A inhibition determines poor outcome and doxorubicin resistance in early breast cancer and its activation shows promising therapeutic effects. Oncotarget 6: 4299-4314, 2015.

24. Li L, Fan B, Zhang LH, Xing XF, Cheng XJ, Wang XH, Guo T, Du H, Wen XZ and Ji JF: Trichostatin A potentiates TRAIL-induced antitumor effects via inhibition of ERK/FOXM1 pathway in gastric cancer. Tumour Biol 37: 10269-10278, 2016.

25. Liu Y, Cao W, Zhang B, Liu YQ, Wang ZY, Wu YP, Yu XJ, Zhang XD, Ming PH, Zhou GB, et al: The natural compound magnolol inhibits invasion and exhibits potential in human breast cancer therapy. Sci Rep 3: 3098, 2013.

26. Pippa R, Dominguez A, Christensen DJ, Moreno-Miralles I, Blanco-Prieto MJ, Vitek MP and Odero MD: Effect of FTY720 on the SET-PP2A complex in acute myeloid leukemia; SET binding drugs have antagonistic activity. Leukemia 28 : $1915-1918,2014$

27. Agarwal A, MacKenzie RJ, Pippa R, Eide CA, Oddo J, Tyner JW, Sears R, Vitek MP, Odero MD, Christensen DJ, et al: Antagonism of SET using OP449 enhances the efficacy of tyrosine kinase inhibitors and overcomes drug resistance in myeloid leukemia. Clin Cancer Res 20: 2092-2103, 2014. 